sutures simply cut out; this was followed by the death of the patient.

The suture has prevented such accidents, and there appears to be less tendency to late ventral hernia. I had tried various methods to be found in books before lighting on this one, of which $I$ have not been able to find a similar description. By it the layers of the abdominal wall can be brought into apposition, each to each, and so held during healing, without tension or necrosis, or on the other hand of yielding. The patient can get up, and the sutures need not be taken out for five weeks. In the case of suppuration fomentations can be put on whilst the sutures continue to hold. The method has been applied also secondarily, after an abdominal incision otherwise sutured has burst open, and sound healing has followed. My description applies in particular to the closure of median abdominal incision, but with modifications I have used the procedure for the closing of other incisions, including cases of ventral hernia and sliding scrotal hernia. The sutures can be inserted even although the abdominal wall is only partly relaxed by the anaesthetic.

\section{The Nethod.}

The soft parts under the skin are held a little everted by Lane's tissue forceps, the skin being retracted as required by a blunt hook. A strand of strong fishing gut has one end threaded through the eye of a semi-circular needle and held by a slip-knot; upon the other end clamp forceps are put on to serve as a stop. The needle is entered (Diagram $1, A)$ one-third of an inch $(1 \mathrm{~cm}$.) from the right margin, through the skin and out through the subcutaneous tissue, the suture being drawn through up to the stop. The needle being then carried across to the left side is made to penetrate the anterior sheath, the left rectus muscle, its posterior sheath, and the parietal peritoneum, not more than two-thirds of an inch $(2 \mathrm{~cm}$.) from the cut edge. The needle is next passed (Diagram $1, B$ ) on the right side through the parietal peritoneum, outwards through the right rectus and its anterior sheath. A second loop is now inserted about half an inch $(1.5 \mathrm{~cm}$.) distant lengthwise from the first loop, the object being to include about one inch of the incision by each suture. The needle is passed (Diagram 1, C) on the left side from the anterior sheath to the parietal peritoneum. Finally the needle is pushed from the parietal peritoneum on the right side outwards (Diagram 1, C, D) to emerge through the skin about a third of an inch $(1 \mathrm{~cm}$.) horizontally outside the point of entry.

The two ends of the suture are drawn upon until, as tested by the thumb and finger, the margins are brought into apposition without constriction or puckering (Diagram 2, E). Then (Diagram 2, F, G, H) the suture ends are knotted over " buttons"; I have used short lengths of well boiled catapult elastic, but rolls of gauze and other things will serve. The skin is thus approximated, and is further held together by a fine continuous suture which can be removed after a few days. At the time or at subsequent dressing a single layer of gause may be slipped under the "buttons" to protect the skin. The sutures should not be taken out until about three (better five) weeks, the patient meanwhile getting about. When doing so the knot is drawn upon sideways, and one end snipped through flush with the skin, into which it withdraws. Later on-whether the same, the next, or the third day-after loosening by the patient's breathing and movement, the suture can be readily withdrawn without liability of breaking or of leaving buried a portion of the fishing gut.

\section{HERPES ZOSTER WITH LOCALIZED MUSCULAR PARALYSIS.}

\section{BY}

CECIL WORSTER-DROUGHT, M.A., M.D.CANTAB., M.R.C.P.

LECTURER IN NEUROLOGY, BETHLEM ROYAL HOSPITAL; ASSISTANT PHYSICIAN, WEST END HOSPITAL FOR NERVOUS DISEASES.

Muscular paralyses in the affected zone accompanying or following an attack of herpes zoster are very rare; especially is this the case in herpes of the trunk. As the essential lesion in herpes zoster is situated in the posterior root ganglion of the spinal nerve supplying the affected area (Von Bärensprung, $1861^{1}$ ) and consists in an inflammation of the ganglion. sheath with round-celled infiltration and extravasation of blood into the ganglion itself (Head and Campbell, $1900^{2}$ ), it is somewhat surprising-when one considers that it is at the posterior root ganglion that the tubular meningeal sheaths of the anterior and posterior roots blend-that the inflammatory process does not spread more frequently to the neighbouring anterior root and result in localized paralysis. That paralysis of muscles in the affected zone is more often met with in herpes of the upper limb than in herpes of the trunk is probably accounted for by the fact that the anterior and posterior roots in the lower cervical region have an even closer relation to each other than have those in the thoracic region. In this connexion, however, it is to be noted that D. W. Montgomery ${ }^{3}$ advances a different explanation. $\mathrm{He}_{\theta}$ believes that herpes zoster is caused by a specific virus-probably streptococcal, as was originally suggested by Rosenow and Oftdale-which reaches the posterior root ganglion from the skin by way of the perineural lymphatics. The fact that the lymphatics of the sensory nerves are more accessible from the surface than are those of the motor nerves accounts for the rarity of ain associated paralysis; in the case of the limb and ocular muscles; however, the motor nerves are more superficial, a discriöution which is considered by Montgomery to explain the relatively more frequent occurrence of motor complications in these situations. In herpes ophthalmicus, ocular patsies as a complication are said to occur in 7 per cent. of cases.

In an extensive search of available literature I have been able to find very few recorded cases of paralysis accompanying or following herpes zoster of the trunk. Gowers mentions the occurrence of motor complications in herpes zoster, and points out that it is necessary to distinguish between immobility from hyperaesthesia and true paralysis. Ebstein $^{5}$ in 1895 collected 20 cases of paralysis complicating herpes zoster, but this series includes no case of herpes of the trunk in which the paralysis followed and was confined to the muscles of the affected zone. The 20 cases consist of 6 of paralysis of certain muscles of the upper limb, 1 of the lower limb, 9 of facial paralysis, 3 of facial paralysis togethè with other cranial nerve palsies, and 1 of ascending myelitis following herpes of the trunk. Hewlett ${ }^{6}$ in $1 \mathrm{C} 0.6$ pointed out that although 76 per cent. of cases of herpes zoster affectẹd the trunk, he had found only one case in which musculapr paralysis occurred. F. Taylor ${ }^{7}$ (1895) recorded a case of herpes on the right side affecting the region of the tenth, eleventh, and twelfth ribs posteriorly and extending to the umbilical region anteriorly, which was followed, about four weeks after the appearance of the eruption, by paralysis of 
the abdominal muscles on the same side. Söderbergh ${ }^{8}$ (1919) described a case of herpes involving the fifth and sixth thoracic segments with slight paralysis of the external oblique on the same side. Several cases of ocular palsies following herpes ophthalmicus and of facial paralysis complicating facial herpes have also been recorded.

In the following case a typical attack of herpes zoster affecting the area of the twelfth thoracic nerve was followed twelve days after the appearance of the herpetic eruption by paralysis of the muscles in the lower part of the abdominal wall of the same side.

A man, aged 61, in December, 1921, while in Australia, had an attack of pain originating in the precordium and radiating down the inner side of the left arm. About a week later he suddenly developed right-sided hemiplegia and aphasia. Both the paresis he left Australia in February, 1922, his speech was practically he left Australia in February, 1922, his speech was practically When first seen (May 19th) the only signs indicating that the patient had had hemiparesis was that the right ankle-jerk was considerably brisker than the left, and the right plantar reflex was less definitely flexor than the left. The cranial nerves, arm and knee jerks, and abdominal reflexes were all normal. He had a certain degree of chronic middle-ear deafness, bone conduction being greater than air conduction, and the tympanic membranes opaque and somewhat indrawn.

The cardiac apex beat was not felt; the area of cardiac dullness extended half an inch external to the nipple line; the first sound was normal, the second accentuated in the aortic area. Pulse 80 , regular, right equal in volume to the left; palpable arteries not unduly thickened; blood pressure, systolic $130 \mathrm{~mm}$. and diastolic $80 \mathrm{~mm}$. Hg. $\boldsymbol{X}$-ray examination showed a slight uniform dilatation of the aortic arch. The patient complained of no particular symptoms.

When seen again (August 5th) he had a typical left-sided herpetic eruption extending from the spine in the lumbar region across the crest of the ilium to the upper gluteal region and round to the groin, just reaching the anterior aspect of the thigh - the area corresponding to the total distribution of the twelfth thoracic nerve. The history was that eight days earlier (July 28th) the boat on which he was leaving England to return to Australia collided with another in mid-channel during the night. He recelved no injury, but being awakened put his overcoat over his night attire and went on deck to ascertain what had happened. The collision necessitated his return to England. Two days later he began to experience severe pain of a neuralgic character in the left loin which radiated towards the groin; the eruption appeared on the fourth day of pain. The patient was not taking arsenic.

Ten days later (August 15th) he stated that a "rupture" had developed in the affected region, and that for the last few days the side had felt somewhat numb. There was a marked "bulge", in the lateral abdominal wall, immediately above the iliac crest. The local musculature was flaccid and failed to contract either on voluntary effort or on coughing; either act resulted in the umbilicus being drawn over towards the right side. To faradism there was no response in the affected muscles. The patient now complained of pain radiating from the loin to the hypogastrium, but said that the region of the hip and groin felt numb. On testing a narrow area of cutaneous hyperaesthesia was found just above and almost parellel with the groin, while below this area and andending backwards to within two inches of the spine was a zonecorresponding with the now fading eruption-of anaesthesia to light touch (cotton-wool) and pin-prick, the area of loss to pain being slightly larger and enclosing that of loss to light touch (anaesthesia of root type over a portion of the cutaneous area supplied by the twelf th thoracic nerve).

Other physical signs-nervous and circulatory systems-shower no change from those previously described, with the exception that the systolic blood pressure was now $120 \mathrm{~mm}$. The Wassermann reaction (blood-scrum) was negative.

\section{REFERENCES.}

'Von Bärensprung: Ann. des Char. Krankheit., 1861, ix, 41. 'Head and Campbell: Brain, 1900, xxiii, 353. '3 Montgomery, D. W.: Arch. of Dcr

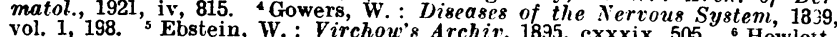
vol. 1, 198. '5 Ebstein, W.: Virchow's Archiv, 1895, cxxxix, 505. ${ }^{6}$ Hewlett, A.: Californian State Journ. Med., April, 1906. 'T. Taylor: Guy's Hospital (Med. Science Abstr., 1920, i, 513).

THE International Congress of Medical Hydrology and Climatology will be held at Brussels from October 20 th to
22nd.

ACCORDING to the official report recently published, during the first six months of 192229,264 cases of cholera occurred in the three Soviet republics of Russian Europe, 4,963 in Caucasia, 1,864 in Aslatic Russia, 2,139 on the railways, 45 on the rivers and canals, and 840 in the Red army.

THE triennial prize of 1,800 francs instituted by Mme d'Ault du Mesnit in honour of her husband for the best. unpublished work on prehistoric anthropology will be a warded for the first time in 1924. Candidates are required to send three typewritten copies of their manuscript to the Secretary, Ecole d'Anthropologie, 15, Rue de l'École de Médecine. Paris. before December 31st, 1923.

\section{ftemaranda:}

\section{MEDICAL, SURGICAL, OBSTETRICAL.}

\section{HAY FEVER TREATED BY SINUSOIDAL CURRENT} TO THE SPINE.

THE following record, which applies to a case treated last summer, may be of interest at a time when this distressing malady is prone to attack its victims.

On June 2nd, 1922, a man aged 33 came to me in a typical attack of hay fever. In previous summers he had tried all the usual remedies, and had been examined and treated by competent nose and throat specialists, but in spite of treatment the trouble was wont to run its course without abatement. He knew exactly the week in which the complaint would commence every year, and it was severe enough to keep him from business while it lasted.

An indifferent pad 4 by 6 inches was applied over the sacrum and an active electrode, 1 inch in diameter, held over the seventh cervical spine. T'he sinusoidal current was gradually turned $\mathrm{cn}$ until he took as much as he could stand without discomfort. Within three minutes there was an improvement. He commenced to take deep inspirations, the general distress lessened, the tickling in the throat and the inflammation and irritation in the eycs subsided. In an incredibly short time, certainly not more than five minutes, he pronounced himself quite normal. The current five minutes, he pronounced himself quite normal. The current

There was no unpleasantness from the current, but he noticed a peculiar metallic taste in the mouth. $\Lambda$ t subsequent sittings he stated that the relief seemed to come as soon as he felt this metallic taste. We discovered later that the metallic taste could be produced by applying the active electrode to various areas in the cervical region, but the relief only came when the pad was held over the seventh cervical spine.

On the day following his first treatment he motor-cycled to business and back without goggles, and felt perfectly well til on his way home, when the symptoms returned, but in a mild degree. Similar treatment was employed, with the same beneficia result. He remained free from trouble till June 9th, and was treated on June 10th. Subsequently he received treatment on June 13th, 14th, 17th, 26th, 29th, and again on July 10th-altogether nine treatments. During this time the discomfort was much less, he slept well and went to business daily.

The result is probably produced by some action on the sympathetic system. Whether one may hope to produce a permanent cure is problematical, but the method seems worthy of extended trial.

Thomas Marlin, M.D.,

Medical Officer in charge Electro-therapeutic Department, University College Hospital.

\section{TWO CASES OF ACUTE INTUSSUSCEPTION IN} CHILDREN : RESECTION : RECOVERY.

ON March 7th, 1923, at the Royal Liverpool Children's Hospital I operated on a boy, aged 2 years, who had suffered from periodic attacks of pain in the umbilical region and vomiting which had become persistent. The symptoms had lasted for seventy-two hours. He showed signs of abdominal distension, had visible peristalsis, and a tumour palpable in the subumbilical region. At the operation $I$ found an ileoileal intussusception which was irreducible and gangrenous. I resected 18 inches of ileum and performed a lateral ileoileal anastomosis. He made a complete recovery.

On March 22nd, at the same hospital, I operated on a boy, aged 10 years, who for thirty-six hours previously had suffered from periodic attacks of severe abdominal colic accompanied by vomiting which had become persistent. In this case there was a large visible tumour extending from below the umbilicus to the right iliac fossa. This intussusception was also quite irreducible and gangrenous. On attempts being made to effect a reduction, the outer coat commenced to split in several places. I removed the whole mass (which consisted of $3 \frac{1}{2}$ feet of ileum), infolded the ends, and as the distal infolded end was close up to the ileo-caecal valve I performed lateral ileo-colic anastomosis. This boy has also made a complete recovery.

In a paper I read before the Liverpool Medical Institution in November, 1922, I stated that 66 per cent. of such cases began as ileo-ileal intussusception. These are examples of cases that remain ileo-ileal. An interesting feature of these two cases is that neither patient passed any blood per rectum.

The importance of the periodicity of the colic in intussusception cannot be exaggerated. It is invariably present in the early stages of the attack.

Liverpool.

W. A. Thompson, M.Ch., F.R.C.S.Ed. 